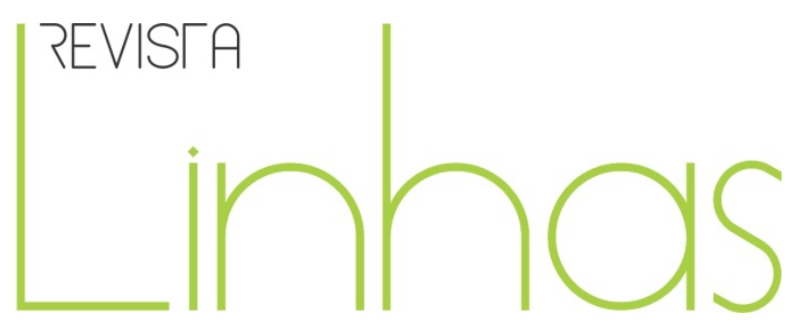

\title{
As cartas de pedidos na correspondência do educador católico Alceu Amoroso Lima: 1928-1945*
}

\begin{abstract}
Resumo
Este artigo foi escrito com a finalidade de apresentar pedidos de um grupo de católicos - Alexandre Correia, Sebastião Leme, Gustavo Capanema, Leonardo Van Acker e Theobaldo Miranda Santos presentes na correspondência do educador católico Alceu Amoroso Lima (1893-1983).Trata-se de abordar o aspecto "sociabilidade" que integra a trajetória de alguns intelectuais, que pode ser investigado nos conjunto de cartas encontrado. Essas missivas passaram por dois tipos de tratamento. O primeiro conjunto - de 25 cartas - se compõe de respostas de Gustavo Capanema, ministro da Educação de 1934 a 1945, a pedidos recebidos por Alceu Amoroso Lima e por ele encaminhados ao ministro. Buscamos analisar-lhes o conteúdo, essencialmente pedidos de ocupação de cargos públicos. Um segundo conjunto - de 15 cartas - é de pedidos feitos diretamente a Alceu Amoroso Lima. Devido à diversidade dos assuntos, foi preciso uma leitura mais específica de cada carta. A análise dos dois conjuntos permite afirmar que a correspondência foi fundamental para o estreitamento dos laços entre os intelectuais católicos e para o prosseguimento do projeto de ampliação do espaço de sua atuação na sociedade brasileira no período destacado - 1928 a 1945.
\end{abstract}

Palavras-chave: História da educação; História de intelectuais; Alceu Amoroso Lima.

\section{Para citar este artigo:}

SILVA, Valéria Jacó da. As cartas de pedidos na correspondência do educador católico Alceu Amoroso Lima: 1928-1945. Revista Linhas. Florianópolis, v. 16, n. 30, p. 104 - 121, jan./abr. 2015.

DOI: $10.5965 / 1984723816302015104$

http://dx.doi.org/10.5965/1984723816302015104

\footnotetext{
* Este texto é parte da dissertação de Mestrado defendida no Programa de Pós-Graduação em História da Unesp-Assis, no ano de 2004. O texto, inédito, foi revisto após o término de minha graduação em Pedagogia na Universidade Estadual de Londrina, no ano de 2012.
} 


\title{
The letters of requests in the correspondence of catholic educator Alceu Amoroso Lima:
}

\section{8-1945}

\begin{abstract}
The goal of this paper is to introduce the requests in the correspondence between the catholic educator Alceu Amoroso Lima (1893-1983) and a group of catholics: Alexandre Correia, Sebastião Leme, Gustavo Capanema, Leonardo Van Acker e Theobaldo Miranda Santos. The article is about to approach one aspect of sociability, which integrates some intellectual trajectories, and the letters have this possibility of investigation. Those letters had two kinds of treatment. One of the groups had 25 letters as responses from Gustavo Capanema, Minister of Education from 1934 to 1945 , to the requests made to Alceu Amoroso Lima that were forwarded to the minister. We search to draw a reflection about the subjects of those letters which treat essentially about occupation of public posts. The second group of 15 letters are requests made directly to Alceu Amoroso Lima. Due to the diversity of the requests of those letters, it was necessary a specific reading of each one. The analysis of those letters of requests made to Alceu Amoroso Lima permits to affirm that the correspondence was fundamental to narrow laces between Catholics intellectuals and to take ahead the project of enlargement of the space of actuation of Catholics in the Brazilian society in the pointed period, from 1928 to 1945.
\end{abstract}

Keywords: History of education; History of intellectuals; Alceu Amoroso Lima. 
Alceu Amoroso Lima teve uma vida longa e intensa. Nasceu na cidade do Rio de Janeiro, em 1893, e faleceu em 1983, em Petrópolis. Seu ambiente familiar era laico. Teve como preceptor, no ensino das primeiras letras, João Kopke (1852-1926), kantiano, laicista, divulgador do método intuitivo de alfabetização. Deu continuidade a seus estudos no Ginásio Nacional, público e laico, que, posteriormente, em 1911, passou a ser chamado de Colégio Pedro II. Em 1913, tornou-se bacharel em Ciências Jurídicas pela Faculdade de Direito de São Paulo.

Quando se voltou para o catolicismo, em 1928, Alceu Amoroso Lima era um intelectual de valor reconhecido e se dedicava com seriedade à crítica literária desde o final dos anos 1910. A partir do momento em que firmou laços com a elite eclesiástica, sua vida ganhou outra dimensão. Empenhou-se em trabalhar em prol de variados projetos católicos que, em grande medida, eram políticas para o País, que dependiam, muitas vezes, da ação do Estado, o que implica deduzir que, para serem efetivadas, demandavam recorrer a negociações.

Em razão disso, configuraram-se relações consideráveis no mundo intelectual, no mundo religioso católico e no mundo político, dimensões que também constituíram o sujeito histórico Alceu Amoroso Lima, do qual procuramos estudar as cartas recebidas entre 1928 e 1945, com particular atenção para a marcante confluência entre esses mundos.

Nesse período, a Igreja caracterizou-se pela tenacidade com que encampou o seu projeto de reocupação de espaços na sociedade brasileira, que acreditava terem decrescido desde a Proclamação da República, em 1889. Para os católicos, a educação tinha importância fundamental, porque, segundo eles, somente ela poderia sanar o problema da crise de consciência, ou a crise de intelecto, nascida da substituição do espiritualismo que ligava o homem a Deus pela inteligência guiada por razões humanas. Era necessário negociar esses espaços com toda a sociedade, especialmente com a elite 
dirigente. Para essa empreitada, a aproximação da instituição Igreja com a intelectualidade foi fundamental (OLIVEIRA, 2012).

Durante o período em análise, de sua conversão ao fim do governo de Getúlio Vargas - de forte presença do autor junto ao Ministério da Educação -, Alceu Amoroso Lima estabeleceu relações muito próximas com a elite política brasileira, antiliberal, que ascendeu após a Revolução de 1930. Essas relações representaram um canal aberto à concretização do projeto maior da Igreja, que consistia na catolicização do País, em andamento desde a Primeira República, e que se desdobrou na ampliação da base de atuação moral, social e política do grupo católico (GOMES, 1999). O projeto ganhou amplitude nos anos de 1920, sobejado, também, pelo alargamento de possibilidades técnicas de comunicação, das quais os religiosos começaram a fazer uso, como o recurso a revistas, destacando-se, entre elas, A Ordem, cujo lançamento, em1921, significou, de acordo com Angela de Castro Gomes (1999 p. 52), a "materialização organizacional do projeto de expansão da Igreja particularmente voltado para a intelectualidade". Ao ser fundado em 1922, o Centro Dom Vital assumiu a publicação d’A Ordem.

Além dessas instituições criadas pelos católicos, a correspondência trocada entre intelectuais também se constitui como lugar de sociabilidade. Há que se perguntar se a correspondência seria um espaço de acertos dos projetos católicos, especialmente os concernentes ao campo educacional, se efetivamente se constituiu numa instância do processo de viabilização de tais projetos. Trata-se também de verificar o que movia esses intelectuais a escreverem cartas, no caso, a Alceu Amoroso Lima, para se ter a dimensão do valor da correspondência como meio de ampliação do poder do grupo católico em seu projeto de recatolicização.

\section{O recurso às cartas}

As cartas foram gradativamente substituídas pelo telefone ao longo do século XX nas variadas motivações para usá-lo, excetuando-se, é claro, as situações que exigiam mais formalidade, como registro escrito. O declínio do uso da correspondência foi ainda 
mais acentuado pela difusão do correio eletrônico, o e-mail, que, se por um lado revitalizou a escrita, por outro tornou ainda mais raro o recurso ao suporte papel. Entretanto, no Brasil dos anos 1930, pouquíssimas pessoas tinham telefone em casa. Segundo Verena Alberti, em 1936 havia no País cerca de um telefone para cada 273 habitantes, mas boa parte dos aparelhos ou pertencia às próprias empresas telefônicas, ou ainda a estabelecimentos comerciais (ALBERTI, 2002, p. 281).

Ocorriam conversas ao telefone entre Alceu Amoroso Lima e os emitentes de sua correspondência, mas não o suficiente para substituir integralmente a prática da escrita de cartas, meio que garantia a circulação do escrito e a prática da leitura, que consolidam sociabilidades culturais.

Mesmo o analfabeto poderia enviar e receber notícias por meio das cartas, como bem assinalou o historiador francês Daniel Roche (2001), estudioso do século XVIII, recorrendo ou a terceiros próximos a ele, ou ao "escrevedor" de cartas, ou ainda ao escrivão público, sujeitos possuidores desse pequeno capital cultural.

Ainda que houvesse a possibilidade do serviço ou da ajuda prestados para a escritura e leitura de cartas, não possuir tais saberes era um impedimento de difusão dessas práticas na sociedade brasileira. Para termos uma ideia, o censo de 1920 aponta que, dentre os brasileiros com mais de 15 anos, 64,9\% eram analfabetos (FERRARO, 2002, p. 34).

Já os missivistas estudados integravam o privilegiado grupo que tinha tido acesso à instrução. Escreviam suas próprias cartas, que evidenciam sua formação culta, clareza de ideias, referências a textos, a livros, e citações, quer em português, quer em francês, idioma predominante à época nos círculos cultos.

A correspondência recebida por Alceu Amoroso Lima aborda vários assuntos relativos à educação, como publicação de livros que visavam a se contrapor aos ideais escolanovistas ou sobre a criação de uma universidade católica. Há também cartas que dizem respeito às organizações ou a estruturas erigidas pelo grupo para atuar no espaço público e nos debates políticos, como ocorreu durante a Assembleia Constituinte de 19331934. No envolvimento dos missivistas com assuntos relativos à educação, os pedidos de 
favores na correspondência recebida por Alceu Amoroso Lima despertaram nossa curiosidade.

Em sua vida, as cartas tiveram grande importância. No ano de 1928, definido como ponto inicial de referência temporal deste estudo, dois aspectos merecem ser mencionados. Em 1928, finda a troca de correspondência com Jackson de Figueiredo (1891-1928), iniciada em 1924, com a morte de seu amigo. Afirmava Alceu Amoroso Lima que foi pela intervenção desse amigo que ele havia recuperado a fé católica, convencido de que seu lugar era entre a intelectualidade da mesma confissão. Também de 1928 é o texto de autoria de Amoroso Lima que marca sua inserção no engajamento nos projetos católicos, em cujo título usa o termo 'carta' - Adeus à disponibilidade: carta a um amigo -, dirigida a Sérgio Buarque de Holanda (1902-1982). Tece considerações a respeito do impacto do final da Primeira Guerra Mundial, evento que teria marcado, de fato, o final do século XIX, e pondera sobre o peso do conflito, suas consequências para sua conversão e sua mudança de postura no período pós-guerra (MEDEIROS, 1978, p 222).

O movimento de recatolicização tinha como centro irradiador o Rio de Janeiro. Lá estavam as lideranças tanto no tocante ao clericato, na pessoa de Sebastião Leme (18821942), quanto no do laicato, por meio de Alceu Amoroso Lima. Deve-se salientar que a coordenação que exercia Sebastião Leme junto à intelectualidade, antes como arcebispo e depois como cardeal, além de ser vista pelo próprio como cumprimento de uma missão, estava ancorada em sua formação teológica. As boas-vindas dadas a Alceu Amoroso Lima à missão, por parte dele, não eram somente de cunho pessoal, mas também da instituição Igreja, embora, em 1928, não ocupasse a posição de maior autoridade católica no Brasil':

É que uma nova primavera sorri nos campos do Senhor. Preparada pelo céu ela desabrochou nas sombras de um túmulo querido.

A pena do escritor, a espada gloriosa do soldado de Cristo sincero do amigo, a firmação melhor, a vocação social católica e brasileira de Jackson de Figueiredo não teve o seu epílogo nas praias trágicas da

\footnotetext{
${ }^{1}$ Sebastião Leme da Silveira Cintra foi nomeado cardeal em 1930, após a morte do cardeal Arcoverde, responsável pela Sé Metropolitana do Rio de Janeiro. Passa a ser a maior autoridade eclesiástica, não apenas dessa sé, mas de todo o Brasil.
} 
Tijuca. A alma boa do cristão foi recebida no seio luminoso do Senhor, [...] a sua bandeira, essa ficou. Nas mãos de Alceu ela palpita de fé e amor.

Teria previsto Jackson a aprovação unânime do novo Elyseu?

Não sei; sinto, apenas, quanto ele deve estar contente de ver que do seu túmulo soprou um vento de Pentecostes para a alma do nosso Alceu. (Sebastião Leme, 24 de dezembro de 1928)

Essa carta, vazada em vocabulário que exprime a sensibilidade católica, foi escrita em 24 de dezembro de 1928, data carregada de simbolismo. Embora fosse véspera de Natal, alude à Páscoa, que celebra a morte e ressurreição de Jesus Cristo, ao referir-se à festa de Pentecostes que, por sua vez, celebra o momento do envio dos apóstolos à missão de evangelizar. Investia o recém-convertido Alceu Amoroso Lima de uma missão a ser desempenhada, e que ele abraçou com ardor.

A abrangência do projeto de recatolicização era de âmbito nacional; havia, porém, uma distância espacial entre os intelectuais católicos. Ao se estudar as cartas enviadas a Alceu Amoroso Lima, logo se percebe o quanto era relevante e imprescindível recorrer a esse meio de comunicação para a troca de ideias entre esses intelectuais. Entre os educadores missivistas, cumpre informar que Leonardo Van Acker (1896-1986) e Alexandre Correia residiam em São Paulo, capital; Theobaldo Miranda Santos (1904-1971), em Campos, Rio de Janeiro. Gustavo Capanema foi correspondente em Belo Horizonte e no Rio de Janeiro. Alceu Amoroso Lima residia no Rio de Janeiro, mas também se deslocava para Petrópolis, onde tinha uma casa de veraneio. Dadas as distâncias entre os missivistas, percebemos que as trocas epistolares não eram um meio para somente vencer a distância espacial. Tinham a função também de suprimir a distância social criada pela vida intelectual, cheia de compromissos, desses sujeitos sociais ${ }^{2}$.

\footnotetext{
${ }^{2}$ Marlon Solomom estudou as cartas de imigrantes alemães no Vale do Itajaí, Santa Catarina, com parentes que ficaram na Alemanha. Afirma que a escrita de tal correspondência "freqüentemente revelava a possibilidade de suprimir o espaço através da memória e de reencontrar os seus entes queridos, sua conservação, a possibilidade de imaginar as novas situações em que se encontravam os imigrantes a distância e, ainda, a impossibilidade de esquecer que um dia partiram" CF. SALOMON, Marlon. As correspondências: uma história das cartas e das práticas de escrita no Vale do Itajaí. Florianópolis: Editora da UFSC, 2002. p. 20.
} 
Outro aspecto que explica a escritura de cartas é o fato de se constituir como um elemento facilitador no processo de troca de ideias, isto é, não atrapalhava o andamento das atividades dos missivistas e evitava os deslocamentos para conversas. Ademais, possivelmente escolhiam um momento mais apropriado para eles mesmos, como emitentes, e evitavam também conturbar a vida do destinatário com visitas, como comentou o próprio Capanema: "Não vou a sua casa para não perturbar o seu tão rigoroso horário"(Gustavo Capanema, 24 de maio de 1945).

A correspondência que Alceu acumulou como destinatário revelou-se um terreno fértil para descobrir as marcas das relações sociais entre os integrantes dessa intelectualidade; neste sentido, muitos assuntos podem ser identificados. A seguir, exploraremos as cartas de pedidos.

\section{Os pedidos}

Há, dentre as missivas recebidas por Amoroso Lima, dois tipos de cartas de pedidos: respostas de pedidos, 25 cartas, que são os encaminhamentos de Gustavo Capanema às solicitações feitas por Alceu Amoroso Lima, e os pedidos feitos a Amoroso Lima, 15 cartas.

No primeiro conjunto, o das respostas de Gustavo Capanema aos encaminhamentos de pedidos feitos a Amoroso Lima, apenas uma é do período anterior ao de sua participação no governo Vargas. Trata-se da missiva datada de 21 de março de 1932. Como as demais que compõem a tipologia, dizem respeito, principalmente, a pedidos de ocupação de cargos. Por meio de tais cartas, podem-se acompanhar, dentro dos limites da atuação de Alceu Amoroso Lima, os arranjos para a obtenção dos mais variados postos, como o de inspetor de escola ou o de censor cinematográfico.

Esse conjunto de 25 cartas foi organizado em quadro (quadro 1). Entre os pedidos para os quais Amoroso Lima obteve resposta, há apenas um relacionado à Saúde, o que reforça a ideia da especificidade de sua ação, voltada à educação, apesar de a Saúde 
compor também o campo de atuação da pasta ocupada por Capanema. Os pedidos eram os seguintes:

\section{Quadro 1 - Classificação das cartas de pedidos}

\begin{tabular}{|ll|}
\hline Respostas de pedidos: & número absoluto \\
\hline & 1 \\
Servente na Biblioteca Nacional & 1 \\
Cargo na Diretoria de Contabilidade & 1 \\
Amanuense na Biblioteca Nacional, & 1 \\
Direção de escola & 3 \\
Inspetor de escola & 2 \\
Cargo na censura cinematográfica & 1 \\
Amanuense do Hospital Psiquiátrico & 1 \\
Amanuense da Biblioteca Nacional & 1 \\
$3^{\text {o oficial }}$ & 1 \\
Nomeação (cargo não mencionado) & 1 \\
Nomeação para arquivista do Colégio Pedro II & 1 \\
Carta de recomendação de Capanema & 1 \\
Taquígrafo no Ministério da Educação & 3 \\
Cargo não citado & 1 \\
Transferência para inspetoria do Colégio Pedro II & 1 \\
Transferência de professor & 1 \\
Cargo na Faculdade Nacional de Filosofia & 1 \\
Recomendação do Ministro a Escola Nacional de Belas Artes & 1 \\
Recomendação para nomeação na Faculdade Nacional de Filosofia & 1 \\
Recomendação para cargo (não mencionado) no Museu Histórico Nacional & 1 \\
& 25 \\
\hline
\end{tabular}

Fonte: CAAL - Centro Alceu Amoroso Lima para a Liberdade

Os sujeitos que recorriam a Alceu Amoroso Lima para ocupar postos são desconhecidos. Se seus pedidos fossem feitos a Amoroso Lima por meio de missivas e tivéssemos acesso a esses documentos, tais trocas epistolares não seriam notáveis, como as que se encontram na obra Prezado Senhor, Prezada Senhora: estudos sobre cartas, organizada por Walnice Galvão e Nádia Gotlib (2000). Ainda assim, quando apenas organizadas em listas, as referências a essas acomodações nos postos públicos portam certa frieza, que eventualmente poderia ser atenuada se laços sociais unissem os sujeitos. O que se nota é que os pedidos recorrem a adjetivos com a finalidade de evidenciar qualidades técnicas, morais ou políticas dos remetentes. Porém, há elementos não ditos, fidelidades não reveladas, antigos favores a serem pagos. Há também relações de amizade e confiança, cultivadas tanto nos ambientes profissionais quanto no âmbito da 
vida privada. A correspondência é um dos meios pelo quais se estreitam laços sociais: o estudo desses casos permitiria acompanhar as negociações, fundamentadas, muitas vezes, em fidelidades com origem em amizades.

O historiador José Murilo de Carvalho pesquisou a correspondência enviada a Rui Barbosa quando ocupou o cargo de ministro da Fazenda, de 15 de novembro de 1889 a 21 de janeiro de 1891 (CARVALHO, 2000). Constatou que nada menos do que $40 \%$ da correspondência dizia respeito a pedidos de favores. Para o autor, a importância dessa correspondência residia menos em revelar quem fazia os pedidos e o que pedia, do que no desvendamento da razão clientelística, isto é, nos valores sociais e na visão do governo que sustentavam moralmente os pedidos, revelados nas justificativas dos pedidos (CARVALHO, 2000, p. 94).

Segundo o autor, a Monarquia e a República mantiveram a prática clientelística: “A retórica republicana sobre a igualdade e o mérito era em grande parte isso: retórica" (CARVALHO, 2000, p. 111). O clientelismo ainda estava profundamente enraizado na sociedade brasileira.

Rui Barbosa, por seu turno, era um liberal que acreditava no Estado de direito, na igualdade perante a lei, enfim, um crítico contumaz da prática clientelística, que, mais forte do que ele e do que outros políticos que a reprovavam, persistia. Nesse período, começava a surgir a ideia da necessidade de burocratizar e racionalizar o serviço público brasileiro. Havia, portanto, uma mudança em curso, que se institucionalizou justamente no período Vargas.

Nas respostas de Capanema aos pedidos de Alceu, constata-se a presteza do ministro da Educação e Saúde em respondê-los. Quando não os atendia, justificava o porquê e apresentava desculpas. Capanema deixava claro que os que eram "recomendados" por Alceu podiam contar com o seu o apreço. Em uma das cartas, datada de 30 de outubro de 1934, o ministro afirma "fazer ótimo conceito, baseado nas palavras com que $V$. o recomendou ao meu apreço e que, vindo de sua parte, constituem sempre um elemento seguro de apreciação moral e intelectual"; contudo, não poderia designar o recomendado, Antonio Alvarenga Filho, para o cargo de diretor da Escola de 
Aprendizes Artífices de Campos, pois o cargo seria ocupado por um funcionário de carreira, cujos esforços o faziam merecer tal premiação.

Verifica-se, nas respostas de Capanema, que, de fato, nos anos 1930 e 1940, continuava a prática de buscar concessões e favores governamentais por meio do empenho, ou seja, “o pistolão, o pedido, a recomendação, a intermediação, a proteção, o apadrinhamento, a apresentação" ( CARVALHO,2000, p. 84). Capanema e Amoroso Lima não se furtaram à prática, apesar de o segundo não pertencer à elite dirigente. Sua proximidade com o ministro proporcionava-lhe oportunidades de intervenção em favor de seus protegidos. De outra parte, já é patente que se burocratizava e racionalizava a administração pública em relação a provimento de cargos, ainda que não generalizada. Considerando as 25 cartas de respostas, em apenas cinco, o motivo alegado para o não atendimento era ser o cargo ambicionado objeto de concurso. É pertinente citar um trecho de uma delas, de 17 de outubro de 1934:

Sobre a pretensão do estudante Alexandre Palmeira, que v. me encaminha em sua carta de 4 de outubro, a Diretoria de Contabilidade presta-me seguinte informação:

'O preenchimento das vagas existentes nesta Diretoria está dependendo da realização de concurso, de acordo com o despacho do Snr. Presidente da República e na forma da alínea $2 a$ do art. 170 da Constituição.

Confirmando as palavras da minha carta de 12 de outubro, julgo, entretanto, que o rapaz deverá aguardar a realização desse concurso que abrirá, sem dúvida, uma oportunidade feliz. (Gustavo Capanema, 17 de outubro de 1934)

Nas outras, havia, obviamente, pedidos aceitos e não aceitos. O que interessa ressaltar é que a maioria era para cargos que, pelo menos em tese, deveriam ser preenchidos por concurso público.

Estas cartas de pedidos, se, por um lado, revelam o quanto Alceu pedia a Capanema, por outro, demonstram, indiretamente, o quanto Alceu era requisitado por terceiros. 
Já as 15 cartas de pedidos dirigidos a ele diretamente revelam um caráter mais diversificado, o que demandou um olhar mais qualitativo, podendo ser de cunho profissional, político ou pessoal. Nestas, é inegável a importância de Amoroso Lima no grupo católico, o que não constitui novidade. Entretanto, aqui se trata de evidenciar que seu poder, advindo da proximidade com a elite dirigente, lhe conferia alguma notoriedade. A conjunção desses elementos ajuda a compreender a razão de ele ser tão requisitado e demonstra a extensão do seu "poder".

Este "poder" pode ser identificado, por exemplo, nos pedidos feitos pelos missivistas, ligados a funções que exerciam nas instituições de ensino ou entidades católicas. Normalmente, as cartas solicitavam a Alceu Amoroso Lima que proferisse palestras ou para que, usando de suas relações no meio intelectual católico, convidasse terceiros de renome. As cartas de Theobaldo ilustram esse tipo de pedido. Em 10 de maio de 1935, ele informava a Amoroso Lima, a respeito do início do ano letivo no Instituto Católico de Campos, ser desejo de toda a militância da cidade que Everardo Backeuser proferisse a aula inaugural:

Nessas condições, venho solicitar ao caro amigo, a fineza de formular ao prof. Backeuser, em nome do Centro D. Vital e da Associação dos Professores Católicos de Campos, o nosso convite para que ele venha a Campos fazer uma conferência no nosso Instituto. (Theobaldo Miranda Santos, 10 de maio de 1935)

Já em1 ${ }^{0}$ de outubro de 1936, convidava Robert Garric, professor de literatura francesa na Sorbonne, para orientá-los na montagem das “Equipes Sociais" em Campos: “Esse convite foi extensivo ao prezado amigo e querido 'leader' que, por certo, não se negará a voltar aqui para regar novamente a sua plantinha...”. Garric, depois de ter lutado nas trincheiras da Primeira Guerra Mundial ao lado de trabalhadores manuais, foi morar em um bairro popular, onde fundou as “Equipes Sociais". No Rio de Janeiro, por volta de 1938, coordenou a organização dessas equipes, nas quais estudantes e operários se juntavam para receber uma cultura fundamental cristã, católica, por meio de contato que se caracterizava como profundamente humano. 
Nas cartas, os missivistas desculpam-se pelas constantes solicitações e se referem às múltiplas atividades de Amoroso Lima, que, não raro, se via obrigado a declinar dos convites, atitude prontamente compreendida pelos requerentes.

Dentre as cartas de pedidos relacionadas às posições ocupadas pelos missivistas, as de Sebastião Leme e Gustavo Capanema têm um lugar diferenciado. Isto se explica pela espécie de "assessoria" prestada por Alceu Amoroso Lima a ambos: o primeiro, um dos líderes eclesiásticos mais destacados do período; o segundo, o poderoso ministro de Vargas. Sebastião Leme escreveu a Amoroso Lima, em 12 de dezembro de 1929, época em que se encontrava em Friburgo: "Apesar do retiro que estou fazendo com 64 sacerdotes, preciso escrever-lhe duas palavrinhas". O clérigo referia-se às orações em prol do Centro D. Vital (CDV) e da Ação Universitária Católica (AUC) e afirmava que, por ocasião de uma celebração em honra ao papa, pensava em convidar alguns oradores, lembrando que “não ficaria mal um representante da mocidade católica universitária". Finalizava: "Se aprovar a idéia, queira convidar o orador."

Os pedidos de Capanema revelam a confiança do missivista na capacidade de Amoroso Lima em contribuir com projetos, ideias ou em levar a cabo propostas do ministério. Numa dessas cartas, escreveu:

Mando-Ihe os meus mais vivos agradecimentos pela conferência sobre Cayrú, com que V. prestigiou a série de palestras sobre os nossos grandes mortos, promovido pelo Ministério da Educação. O seu trabalho foi, em tudo, digno da nobre figura que ele evocou e que assim se projectou, de maneira luminosa, na estima de nossa gente.

Espero de V. agora novo trabalho: reunir em um volume, editado pelo Ministério, as mais belas páginas de Cayrú. Na certeza de que você prestará mais este serviço às nossas letras, mando-lhe o meu abraço muito cordial. (Gustavo Capanema, 13 de outubro de 1937)

Entre os pedidos, há apenas um, de Capanema, que se caracteriza, explicitamente, como político. Trata-se de telegrama no qual se lê: "Peço-lhe obséquio telegrafar urgente deputado Figueiredo Rodrigues solicitando-Ihe não criar embaraços andamento projeto 
reorganização Ministério. Abraços Capanema" (Gustavo Capanema, 16 de outubro de 1939).

Entre as cartas remetidas a Amoroso Lima, há também as que se referem a arranjar postos, como já foi sugerido acima. Duas merecem destaque: uma de Gustavo Capanema e outra, de Theobaldo Miranda Santos, ambas de 1938, e decorrentes da nomeação de Alceu Amoroso Lima para reitor da Universidade do Distrito Federal (UDF), em dezembro de 1937.

Depois de quase dez anos de militância católica, com atenção especial dedicada à temática da educação, Alceu Amoroso Lima, enfim, passou a exercer um cargo de destaque na área. Sua passagem pela reitoria foi rápida, tendo ficado apenas nove meses. Entretanto, o fato de ter sido reitor da UDF foi representativo, do ponto de vista político, pois, em 1937, deu-se no Rio de Janeiro a consolidação da vitória católica conservadora sobre o grupo escolanovista, liderado por Anísio Teixeira, que coordenara a criação da UDF em 1935 .

Em 11 de agosto de 1938, é Capanema que solicita:

Informada de que existem vagas de assistente no laboratório de psicologia do Instituto de Educação, a professora Iolanda Álvares deseja ser aproveitada em uma delas.

Sobre a candidata posso dizer a V. que se trata de moça culta e distinta, diplomada pela Escola de Aperfeiçoamento de Belo Horizonte e apta, portanto, para o exercício da função que pleiteia.

Venho, assim, solicitar, o seu melhor interesse em favor dessa pretensão e desde já the manifesto os meus agradecimentos pelo que fizer no sentido de atendê-la.

Nos anos de 1930 e 1940, intelectuais, elites dirigentes e a Igreja compartilhavam uma visão hierárquica do social, que preconizava a teorização da política como competência, no sentido de que governar demandava o saber científico (PÉCAUT, 1990, p. 30). É o que explica a presença de tantos intelectuais no governo Vargas e, particularmente, na pasta de Capanema, mesmo que muitos deles fossem mais ligados às artes, como Ronald de Carvalho, Carlos Drummond de Andrade e Mario de Andrade. De 
qualquer modo, tal característica social contrastava com a encontrada em fases anteriores da História do Brasil, nas quais o poder estava mais organizado em razão de legitimações hereditárias ou de propriedade.

De acordo com Sérgio Miceli (1979), a valorização dos diplomas para o preenchimento de postos públicos está associada à expansão de cursos universitários, promovida pelas reformas de ensino, o que aumentou a concorrência na busca de postos variados. Em 1911, a reforma Rivadávia reafirmou as disposições então em vigor, ou seja, da competição livre entre instituições oficiais e privadas, estabelecida pela reforma Benjamim Constant, em 1891, que extinguiu o monopólio que o poder público exercia sobre o ensino jurídico, restringindo-se aos encargos de inspeção e reconhecimento de faculdades por meio do Conselho de Instrução Superior. Em 1892, a referida reforma foi ampliada, vindo a ser aplicada aos demais cursos superiores (MICELI, 1979, p. 36).

O efeito do aumento do número de cursos superiores foi sentido em grande medida nos anos 1930. A importância do diploma foi modificada para os herdeiros da oligarquia. De valor de conquista de apreço social ou, então, como "um sinal de distinção capaz de validar lucros provenientes de outras atividades econômicas das famílias dirigentes", passou a ser usado por aquele que o possuía para se acomodar em algum posto público e para buscar proventos (MICELI, 1979, p. 41). A conjuntura política era favorável, devido à expansão da aparelhagem burocrática do poder central.

$\mathrm{Na}$ correspondência de Alceu, constata-se um movimento interessante. Se é conhecida a presença dos intelectuais no governo de Vargas em cargos importantes e de confiança, uma série de cargos menores também estava em disputa, como comprovou a última carta citada de Capanema. No caso de Alceu Amoroso Lima, há que se considerar que, apesar de ele não integrar de forma direta os quadros do governo, dispunha de um poder significativo. Deste modo, a prática da distribuição de cargos está relacionada ao projeto de catolicização, que queria estender os braços da Igreja em direções estratégicas — o meio intelectual, o sistema de ensino e o operariado.

Theobaldo Miranda Santos, por sua vez, também se refere à presença de Amoroso Lima na UDF, fato que despertou o interesse do missivista em obter uma posição no 
Instituto de Educação, vinculado à mencionada universidade. Em uma série de quatro cartas enviadas entre $1^{\circ}$ e 13 de janeiro de 1938 , mencionava seu desejo de se mudar de Campos - da "província" - para a capital, onde, além de poder desenvolver melhor suas pesquisas relacionadas à pedagogia, estaria perto de Alceu (Theobaldo Miranda Santos, $1^{\circ}$ de janeiro de 1938). Em 13 de janeiro escreveu:

\begin{abstract}
Eu sou uma fatalidade! Como diría Nietzche. De volta da minha passagem meteórica pelo Rio, já estou a incomodá-lo novamente com mais uma carta inoportuna e irreverente. Mas acontece que lendo a organização geral da Escola de Professores do Instituto de Educação, verifiquei que nessa instituição a cadeira de Biologia Educacional está intimamente articulada com a cadeira de higiene escolar, exigindo portanto certas práticas de medicina aplicada que escapam às minhas possibilidade culturais e técnicas, pois, conforme já lhe informei, sou somente graduado em Farmácia, Odontologia e Pedagogia.

Restam na referida Escola as cadeiras vagas de Filosofia da Educação, História da Educação e Educação Comparada, todas elas perfeitamente compatíveis com a minha formação técnica e cultural. Dessas, a que mais me encanta - por que não confessar? - é a de Filosofia da Educação que é mais propícia para a transmissão das verdades totais e eternas da Igreja de Cristo. Mas aceitarei, jubilosamente, qualquer uma das três.
\end{abstract}

Capanema e Miranda Santos ocupam lugares diferentes na correspondência de Amoroso Lima. Percebe-se que a relação entre Capanema e Amoroso Lima é simétrica, enquanto que Miranda Santos se encontrava em situação de dependência em relação a Amoroso Lima. Contudo, mais do que realizar a contabilidade do capital simbólico de cada intelectual, a intenção era mapear as formas de solidariedade e sociabilidade, apreensíveis também pela circulação dos favores, pequenos ou grandes, mas que reproduziam o padrão clientelístico tradicional. Neste sentido, a personalidade dos envolvidos assumiu importância. 


\section{Considerações finais}

Escrever cartas foi uma prática que contribuiu para consolidar sociabilidades culturais. Por meio da correspondência recebida por Alceu Amoroso Lima, foi possível acompanhar algumas articulações dos católicos. Verificamos que os missivistas escreviam cartas para a execução do seu projeto de recatolicização da sociedade brasileira, cuja exequibilidade passava por um engajamento consistente. Para o fortalecimento da militância, os laços sociais baseados na sensibilidade católica e no interesse acerca do tema da educação, obviamente, foram importantes, mas tais afinidades abriram espaço para o cultivo de afetividades, como coleguismo ou amizade. Neste aspecto, a fidelidade a tais laços manteve o grupo coeso.

Importante considerar que os projetos coletivos se vinculam também a projetos individuais ou pessoais, daí a pertinência de se fechar o foco de observação em vestígios de indivíduos muitas vezes desconhecidos na historiografia. A consecução de projetos individuais e pessoais dentro do projeto maior católico aparece na correspondência recebida por Alceu Amoroso por meio de pedidos de vários cargos, encaminhados ao ministro Capanema, como de inspetor de escola ou de censor cinematográfico. Outros tipos de pedidos, feitos diretamente a Alceu Amoroso Lima, revelam práticas e saberes da militância católica, como articulação de palestras da intelectualidade católica, preparação de lideranças estudantis católicas, ocupação de cargo de professor e outros.

\section{Referências}

ALBERTI, Verena. O século do moderno: modos de vida e consumo na República. In: GOMES, Angela de Castro; PANDOLFI, Dulce Chaves, ALBERTI, Verena (Orgs.). A República no Brasil. Rio de Janeiro: Nova Fronteira: CPDOC, 2002. p. 261-338.

CARVALHO, José Murilo. Rui Barbosa e a razão clientelística. Dados: Revista de Ciências Sociais, Rio de Janeiro, v. 43. n. 1, 2000. p. 83-117. 
FERRARO, Alceu Ravanello. Analfabetismo e níveis de letramento no Brasil: o que dizem os censos. Educação e Sociedade. Campinas, v. 23, n. 81, dez. 2002. p. 21-47.

GALVÃO, Walnice Nogueira, GOTLIB, Nádia Battella (Org.). Prezado senhor, prezada senhora: estudos sobre cartas. São Paulo: Companhia das Letras: 2000.

GOMES, Angela de Castro. Essa gente do Rio... Modernismo e nacionalismo. Rio de Janeiro: FGV, 1999.

MEDEIROS, Jarbas. Alceu Amoroso Lima. In: . Ideologia autoritária no Brasil, 19301945. Rio de Janeiro: FGV, 1978. p. 219-378.

MICELI, Sérgio. Intelectuais e classe dirigente no Brasil (1920-45). São Paulo: Difel, 1979.

OLIVEIRA, Lúcia Helena Moreira de Medeiros. O pensamento educacional católico restaurador - uma análise dos documentos pontifícios da Primeira República. Cadernos de História da Educação. Uberlândia, v. 11, n. 12, jul/dez. 2012.p. 501-517.

PÉCAUT, Daniel. Os intelectuais e a política no Brasil: entre o Estado e a Nação. Trad. Maria Júlia Goldwaser. São Paulo: Ática, 1990.

ROCHE, Daniel. As práticas da escrita nas cidades francesas do século XVIII. In: CHARTIER, Roger (Dir.). Práticas da leitura. Trad. Cristiane Nascimento. 2. ed. São Paulo: Estação Liberdade, 2001.

SALOMON, Marlon. As correspondências: uma história das cartas e das práticas de escrita no Vale do Itajaí. Florianópolis: Editora da UFSC, 2002.

Recebido em: 09/11/2013 Aprovado em: 12/02/2014

Universidade do Estado de Santa Catarina - UDESC Programa de Pós-Graduação em Educação - PPGE Revista Linhas Volume 16 - Número 30 - Ano 2015 revistalinhas@gmail.com 